\title{
RULES OF DESCENT IN SIXTEENTH CENTURY YUCATAN *
}

\author{
by William A. HAVILAND \\ University of Vermont
}

Anthropologists have long shown a fascination with the operation of descent as an important principle of social organization. That such principles are strongly linked with subsistence and residence patterns has been repeatedly asserted (cf. Driver 1961: 319-324). Needless to say, when dealing with American Indian societies which were conquered by Europeans over 400 years ago, it is not always easy to learn which descent principles were in force in those societies. Following the discovery of the Americas, a steady stream of books, pamphlets, and letters were produced to satisfy the curiosity of Europeans about the native inhabitants of the new lands. Though many of the earliest chroniclers were educated, none were trained anthropologists, nor did many have the leisure needed to make thorough studies of their subjects. Furthermore, Indians were regarded with various degrees of prejudice, ranging from a sympathetic attitude on the one hand to outright hostility on the other. Then, too, much of the writing of the early chroniclers was biased by a concern with the Indian's soul, the exploitation of his labor, and the conquest of his land. Hence, their efforts do not necessarily provide us with reliable information on descent.

All of this holds true in the case of the sixteenth century Maya of Yucatan. The sources of information in question have been appraised by a number of people, notably R. L. Roys (1962: 28-31) and A. M. Tozzer (1941). There is an additional problem, recently raised by Hellmuth (1969): namely, that sexteenth century Maya culture in Yucatan may have been far from uniform. Certainly, as Redfield (1941: 87-88) pointed out, there have been a number of dif-

\footnotetext{
- My thanks to Thomas E. Lux, who presented me with a number of fascinating ideas on the basis of his first-hand experience among cognatic societies of Southeast Asia, after reading a first draft of this paper.
} 
ferences from one community to another in recent times. Some differential acculturation may be involved here, however, it remains to be seen whether or not a similar situation obtained for Yucatan on the eve of conquest, and this should be borne in mind here.

In the face of all this, coupled with the confusion there has been among anthropologists on the subject of descent in general (cf. Goodenough 1970: 53), it is scarcely surprising that there is disagreement among anthropologists today about descent among the Yucatan Maya at the time of the Spanish takeover. It is my purpose here to review the various ideas which have been presented on this matter. Some of the comments I will make have appeared elsewhere (Haviland 1968, 1971, 1970a), others appear here for the first time.

There seems no question but what there was a patrilineal reckoning of descent among the Maya of Yucatan, which was the basis for membership in exogamous descent groups. By this I mean there were publicly recognized social entities, that being a lineal descendant of a particular real or fictive ancestor was a criterion of, membership, that use of sex (here, men) was jurally relevant for reckoning one's lineage to that ancestor (cf. Goodenough 1970: 51, 53 ), and that marriages were normally forbidden between people who were members of the social entity. The relevant Spanish and native Maya documents have been reviewed by Roys (1940; 1943 : 35-36; 1957: 4-5; 1965; see also Beals 1932). These indicate that each individual was a member of a named patrilineal unit known as the ch'ibal, which served to regulate marriage and inheritance, and the members of which were obligated to aid one another. In most cases, the name associated with a ch'ibal was of a species of flora or fauna. Each ch'ibal normally had a patron diety, often a deified ancestor. These last characteristics suggest an association of totemism with some, if not all, the ch'ibal, which would imply unknown or merely postulated traditional ancestors for them.

Roys referred to the ch'ibal as a lineage, but noted that "...a good many of them contained too many members and were too widely dispersed to be considered lineages in the anthropological meaning of the term." (Roys 1957: 4) Indeed, a number of patronymics, each associated with a specific ch'ibal, were widely distributed over the Yucatan penninsula (Roys 1940: 36). There is also a significant statement by Landa: 
"... when anyone finds himself in a strange region and in need, he has recourse to those of his name; and if there are any, they receive him and treat him with all kindness; ..." (Roys 1940: 35.)

From these, it would appear that the term sib, rather than lineage, is preferable for the ch'ibal. A sib may be defined as a unilineal construct with few, if any, corporate characteristics, with geographically dispersed membership, and with an unknown or merely postulated common ancestor (Murdock 1960: 1). Indeed, sibs provide an effective basis for individuals to assert claims to one another's protection and hospitality in their movements from one locality to another (Goodenough 1963: 926).

While there is a measure of agreement on a patrilineal reckoning of descent among the Yucatan Maya of conquest times, disagreement arises in that some authorities see evidence for an additional principle of matrilineality (Adams 1969: 26; M.D. Coe 1965: 104, 1966: 144-145; Roys 1940: 37-38; 1943: 36; 1962: 63). Others, however, see none (Driver 1961: map 32; Haviland 1968: 101). Here, the views of Roys, Coe and Adams may be reviewed in historic perspective.

Roys long held that there was both matrilineal and patrilineal reckoning of descent among the Yucatan Maya, although he never used the term "double descent". Interestingly, however, his most recent statement makes no definite reference to matrilineality (Roys 1965; see also Roys 1957). In his earliest statement, Roys (1940: 37-38) reviewed evidence to the effect that a person's appellative (naal) name was inherited matrilineally. Some of these naal names occurred also as patronymics, but others did not. Coupled with this, there seemed to be a special term for one's matriline, as well as patriline. Finally, the Yucatec term for "noble" referred to people whose descent was known on both sides.

In his 1962 publication, Roys added other information. First, the important Chel family derived its high status through descent from the daughter of a noted priest at Mayapan (Roys 1962: 60). Second, Gaspar Antonio Chi, when he sought a subsidy from Spain in 1580, stressed the importance of his maternal ancestors, the Xiu, who ruled the province of Mani (Roys 1962: 53). Third, the occurence of 
matrilocal residence among the neighboring Chontal Maya might indicate matrilineality among the Maya (Roys 1962: 63).

This information could, indeed, be taken as evidence for double unilineal descent reckoning among the Yucatan Maya. However, other alternatives exist, which were not fully understood when Roys initially developed his ideas (cf. Haviland 1971: 219-22). Perhaps this accounts for the caution of his final statement: "Often, a matronymic precedes the patronymic, but the significance of the former is obscure." (Roys 1965: 661-2) Here, I would like to examine Roys' points on order.

As has often been pointed out, ideas of kinship and principles of succession, inheritance, and group membership do not necessarily coincide (Goodenough 1970: 41). Here, as I have pointed out elsewhere (Haviland 1968: 101) inheritance of the naal name does not necessarily indicate affiliation in a matrilineal descent group. Nor should it be assumed that patrilineal descent would result in recognition of a kinship tie with one parent to the exclusion of the other, or even that it was closer. That all but six of the known naal names occurred also as patronymics could be explained if, in the past, the Maya had a cognatic, rather than unilineal, form of social organization such as Murdock's (1960: 14) ambilineal type, an argument I have presented elsewhere (Haviland 1968: 103-104). In some such societies, individuals may be affiliated with their mother's or father's descent group; sex is jurally unimportant for tracing one's lineage to the founding ancestor. In the past, men and women might have inherited their names from their father or their mother, depending on their descent group affiliation. If so, perhaps those six naal names, now unknown as patronymics, were associated with ambilineal descent groups, but with a shift to patrilineal organization, they died out as patronymics.

On the other hand, there are other possible explanations. Perhaps sixteenth century Maya social organization was undergoing a shift in the opposite direction, from patrilineal to ambilineal descent (of which more below). A shift to ambilocal residence would automatically produce a local group of kinsmen, some of whom were related in the male line, and some in the female line, which could have involved a de-emphasis of sex as a criterion for ch'ibal membership. In traditional anthropological parlance, the latter would have changed from a patrilineal to an ambilineal descent construct. Or, perhaps personal (ego-based) kin groups were a part of sixteenth century Maya society. As Goodenough (1961: 1345) has pointed out: 
"... wherever descent groups exist, the one (or more) to which a person belongs or to which he has a direct kinship connection (although he is not a member) are likely to be included in his personal kindred en masse..."

So, perhaps the members of one's mother's cb'ibal were counted as members of one's own personal kindred, and this was reflected in naming practices. Finally, the inheritance of names both from one's mother and father is not unknown in societies which lack descent groups, but in which descent is reckoned bilaterally. In Spanish speaking countries today, a child has suffixed to his surname (i.e., patronymic) that of his mother (her patronymic, his matronymic). Again, in these cases, the six names in question could have died out, to be retained temporarily as naal names.

With respect to the special term for one's presumed matriline, the problem is one of translation. Whether or not this is a correct translation I cannot say; perhaps the term refers simply to one's maternal relatives. Almehen, the term for noble, clearly involves this concept. Here, al refers to a woman's offspring, and meben to a man's progeny (Roys 1943: 33). Conquest-period practices among the cognatic societies of the Valley of Mexico may be instructive here (Haviland 1971). Among these there was a regular system of marriage alliances among Mexican royal families, such that a person of high status had prominent relatives on both maternal and paternal sides. Perhaps such a system was practiced by the Maya. Indeed, naal names seem to have been known generally only in the case of prominent families, rather than the less well-to-do, which would suggest that the mother's genealogy was of little consequence for most people. Perhaps, then, there was a class-associated difference in descent reckoning among the Maya. The phenomenon is not unknown (c.f. Goodenough 1970: 20-21); for example, among the Lue Tai of southeast Asia, the nobility conform closely to a patrilineal type of organization with patrilocal residence, while the commoners are bilateral, with ambilocal or neolocal residence (Lux 1965: 6). In this case, the upper-class practice results from close ties to India. So far as the Maya are concerned, there is some evidence that the nobles considered themselves as descended from Mexican invaders (Roys 1957: 5).

Roys' example of the Chel familiy fits the above interpretation very nicely. So, too, does the petition of Gaspar Antonio Chi, altthough perhaps not too much weight should be placed on this. $\mathrm{He}$ was, after all, trying to cast himself in the most favorable light to 
the Spanish authorities, and this may have required some falsification. While his falsification would probably have been based on accepted ways of proving high status; whether Spanish or Mayan is not known.

Roys' final point, the supposed matrilocal Chontal Maya, may be disposed of quickly. Elsewhere, I have presented evidence to suggest that the Chontal may have practiced ambilocal ("bilocal") residence, with the further possibility that theirs was a cognatic, rather than unilineal, society (Haviland 1970). Overall, then, Roys' material does not seem to favor matrilineality among the Maya over a number of other alternatives.

M.D. Coe is the first person to specifically propose double descent for the Yucatan Maya. His ideas were worked out in a short article (Coe 1965); a year later, in a general work, we find this very positive statement:

"There is now abundant evidence that these two kinds of name represented two different kinds of cross-cutting and coexistent descent groups: the matrilineage and the patrilineage .... as for the matrilineage, it probably acted principally within the marriage regulation system, in which matrimony with the father's sister's or mother's brother's daughter was encouraged, but certain other kinds forbidden" (Coe 1966: 145).

The "abundant evidence" to which Coe refers is Roys' work on Maya names, discussed above, and an analysis of Maya kinship terminology by Lounsbury (Coe 1965: 104). It is the latter which must now be discussed.

Eggan (1934) was the first to discuss in detail 16th century Maya kinship known from Yucatan. On the basis of certain features of this, he made the suggestion that symmetrical cross-cousin marriage was the norm, which would produce a tendency for households to exchange daughters. If this were the case, it would make the Maya the only known practitioners of cross-cousin marriage in Mesoamerica (Rommey 1967: 223). While this doesn't rule out the possibility, it does place the burden of proof on those who subscribe to the idea. Eggan's case, unfortunately, rests on indirect evidence: The assumption of virtually complete integration between kinship terminology and other elements of social organization, and reports of such a system among societies just to the south of Mesoamerica.

The first assumption is valid in some cases, but not others (Haviland 1968: 99). Among North American Indians, cross-cousin marriage has been found in association with five different kinds of 
kinship terminology. Generally, however, it was permitted or preferred generally by only a minority of peoples. That cross-cousin marriage occurs south of the Maya, then, doesn't necessarily tell us anything about the Maya themselves. So, Eggan's evidence alone is not sufficient to prove his case.

Lounsbury has gone over the same material used by Eggan, and reports a Kareira - type of terminology (Romney 267: 222-3). The Kareira are an Austrailian society with a so-called four section system. Classic analysis interprets these sections as the result of the intersection of patrilineal and matrilineal exogamous descent lines, such that each person winds up marrying a cross-cousin (Buchler and Selby 1968: 145). Hence, the term "double descent" (Buchler and Selby 1968: 281). Their kinship terminology features bifurcate merging - Iroquois terms (for definition, see Goodenough 1970: 115 n. 19 and 116). From this, Coe makes an assumption, similar to Eggan's: Since the Maya apparently had the same terminology as the Kareira, descent and marriage were also the same. Yet, as Goodenough (1970: 141) points out: "... neither the sections nor preference for cross-cousin marriage in brother-sister exchange are necessarily antecedent to the kinship terminology, however well they fit with it." Coe recognizes the desirability of direct evidence for the system which he proposes, but finds no more than Roys' information on matronymics. He does remark:

"We have from the pens of the early Franciscans many native kin terms, for the prevention of incestuous alliances was a major problem, but we have hardly anything on the social organization of which this vocabulary was a logical expression" (Coe 1965: 98; quoted in Haviland 1968: 99).

Overlooked by Coe is the fact that the church had a ban on cousin marriage in the 16th century (Roys, Scholes, and Adams 1940: 15). Consequently, following Coe, had cross-cousin marriage been the norm in Yucatan, it would have been reported. Not only are there on such reports, but the Cozumel census of 1570 reveals very few cases of cross-cousin marriage there (Haviland 1972; Roys, Scholes, and Adams 1940: 15). So, while there is no positive documentary evidence at our disposal, there is very definite negative documentary evidence.

One final point may be made here with.respect to Coe's argument. Although my own investigations support Lounsbury's conclusion that 
bifurcate merging-Iroquois terms figured in Maya Kinship, it appears that a shift may have been in process to or from bifurcate collateralHawaiian terms (Haviland 1968: 102-103). If so, it is debatable whether the Maya kinship system should be directly compared with that of the Kareira.

Adams' argument may best be stated in his own words:

"Haviland has to refute preceding studies by Roys and M. D. Coe which suggest the possibility of double descent among the Maya. The refutation is based principally on the fact that incest taboos are not extensive on the matrilineal side... this is not a valid objection in as much as it assumes a functional equivalence of both sides. In classic double descent situations the sides are not functionally equivalent. The marriage rules may be handled by the patrilineal side and religious affairs by the matrilineal side. The Maya could simply have assigned distinct functions to the two sides, the matrilineal side not handling marriages and therefore not having any functional necessity for extensive incest taboos." (Adams 1969: 26)

$\mathrm{He}$ goes on, then, to mention possible evidence for matrilineality from a classic Maya site prior to A. D. 900, which need not concern us here (see Haviland 1971 for a discussion of this).

As the reader should by now be aware, my refutation of double descent rests on much more than incest taboos alone. Roys, in fact, never even suggested exogamy in connection with inheritance of the matronymic. On the other hand, Coe's reconstruction, as we have seen, explicitly calls for a matrilineal extension of incest taboos to create a system of marriage regulation with matrilineal, as well as patrilineal exogamy. Presumably, this is the reconstruction which Adams wishes to endorse, yet in doing so, he calls the central feature of it into question.

Since matrilineal extension of incest taboos is required by Coe's scheme, and since such extension normally follows development of matrilineal descent (Murdock 1949: 307), what then, do we find? While all bearers of the same patronymic were covered by incest taboos, on the maternal side, only mother, mother's sister, and her daughter were covered (Haviland 1968: 100). Given Coe's previously cited statement that the early Franciscans were concerned with the prevention of incest, this would seem to be reliable information. This is a far cry from the Kareira, who according to Murdock 
(1949: 306) cover all matrilineal and patrilineal relatives with whom kinship is assumed, even though it cannot be traced genealogically. From the evidence at our disposal, then, a matrilineal descent line, if it existed, was nonfunctional in the regulation of marriage. Since no other functions can be found for it, save for possible inheritance of the naal name, I conclude that matrilineal descent simply was not an important feature of sixteenth century Maya social organization in Yucatan. Moreover, to place the Maya in the same classificatory category as the Kareira is to obscure the very real differences between the two. In fact, to my knowledge, double descent with exogamy has never been found north of the Isthmus of Panama (Driver 1961: Map 32).

\section{III}

In an earlier publication, I developed the hypothesis that patrilineal organization among the Yucatan Maya had developed out of an earlier cognatic form of social organization (Haviland 1968: 103-104). This was based on Murdock's (1949) postulate that the determinants of kinship terminologies are the associations and dissociations of kinsmen under various forms of family and descent group organization, and the like. Further, in the course of change in social organization, descent tends to change later than residence, but earlier than kinship terminology. Looking at the Yucatan Maya in this light, patrilocal residence and patrilineal descent seemed consistent with one another, while kinship terminology suggested a shift from bifurcate collateral-Hawaiian terms, which do not make the kinds of distinctions one would expect where unilineal principles of descent are important, to bifurcate merging - Iroquois terms which do. Now, further information, summarized below, indicates a change in household composition by the mid-sixteenth century. In anthropological parlance, this may be described as a shift from patrilocal to ambilocal residence, although it must be understood that the Maya need not have thought of residential choice in this way (see below). Since the kinship terms in question are those which were in use toward the end of the sixteenth century (Redfield 1941: 197), a more tenable interpretation of the evidence is that a shift from patrilineal to cognatic organization was in process in the sixteenth century. What I mean by this is that sex, as jurally relevant for membership in both household and descent groups, ceased to be 
important to the Maya. This does not necessarily rule out a possible earlier cognatic stage of Maya social organization, but it does mean that evidence for this is not to be found in sixteenth century Maya social organization.

Recent studies of sixteenth century household composition among the widely separated Cozumel Island Maya and Chontal Maya suggest that ambilocal residence was the "rule" for both (Haviland 1972, 1970). So far as the Cozumel Maya were concerned, I suspect the crucial considerations in postmarital residence choice were 1) that they join a household which included other married couples, some members of which were consanguineal kin of the bride or groom and 2) of the various possible households which they could join, they chose that which offered the greatest potential in terms of resources and/or prestige. It is this which I mean when I speak, for convenience, of ambilocal residence. There is reason to believe that this was true for other Maya groups in Yucatan as well (Haviland 1972). My conclusion with respect to Cozumel Island is based on statistics from the year 1570, and I interpret ambilocal residence as a shift from patrilocality, where the couple usually joined a household, the men of which were consanguineal relatives of the groom (normally including his father). This came about in response to a marked population decline which followed the introduction of the White Man's diseases. I suspect, now, that the same conclusion holds true for the Chontal Maya. The statistics here predate those for Cozumel Island by one year. It is known that by 1561 (eight years earlier) the Chontal Maya population had declined $90 \%$ in a period of 36 years (Thompson 1966: 26). This amounts to a major demographic catastrophe, and it seems to me that this could not help but cause a change in aboriginal residence patterns.

Given a change to ambilocal residence, a change in descent reckoning might be expected to follow, with most probably a de-emphasis on sex as a criterion for tracing lineage to a founding ancestor. Such residence inevitably produces a local kin group, some members of which are related in the male, and some in the female, line. Such a group (an ambilocal extended family) amounts to what might be labled for convenience a minimal ambilineal descent group. I view this change as an effort to keep the old descent system working, in order to ensure the orderly inheritance of tangible or intangible property, and the orderly delegation of authority. In the face of demographic disaster, rigid adhearance to patrilineal descent and patrilocal residence would have seen the demise of a number of 
families and descent lines. So, considerations of property and status to be inherited may have caused modification of patrilocality, so as to allow more flexibility of residence choice. Given such a state of affairs, the Maya may still have spoken of the ch'ibal in terms of patrilineal descent, (the ideal) in spite of de facto "ambilineal descent", for this was the traditional basis of affiliation up into the first two decades of the sixteenth century. This would account for the emphasis on patrilineality which is conveyed by colonial documents on the Maya. In the same way, the early Spanish accounts speak of matripatrilocal residence as the norm, as it probably was at the start of the century, even though the trend away from this (to ambilocal residence) was well underway at the time the accounts were written.

In time, de facto ambilineal descent might have produced explicit recognition of the unimportance of sex as a criterion for descent group membership as ideals were reconciled with reality. Perhaps this helps explain inheritance of the naal name. A catastrophic population decline would have been most disastrous to a nobility of restricted numbers, compared to the commoners who made up the vast majority of the population (cf. Roys 1943: 34). Moreover, inheritance of property and transmission of authority were presumably matters of greater importance to a nobility. Thus, flexibility of descent would seem to have been highly important to the survival of elite descent units, which might easily have died out through rigid adhearance to patrilineal descent. Under an ambilineal "rule" with ambilocal residence, a noble descent line could have been perpetuated by a woman's children, in the absence of patrilineal heirs. Inheritance of a name from one's mother could have been tied up with this. Consistent with this interpretation was the particular association of the naal name with, and the importance of maternal relatives to, the nobility. Added to this, all but six of the naal names occurred also as patronymics; the other six may have been connected with ambilineal descent lines which, in spite of all, had very recently died out. With time, one would expect that the commoners in Maya society would have tended to emulate noble practices, but instead, with Spanish consolidation of power in Yucatan, the ch'ibal seems to have withered on the vine. This was probably a consequence of strong political power which contrasts with the previous situation of a number of feuding provinces. With this change, there was open access by members of one local group into another, regardless of descent ties. What was left was a minimal ambilineal descent group in the form of the ambilocal extended family. 
In connection with the proposed shift to ambilineality in Yucatan, it may be noted here that there are hints of such organization among the Chontal Maya of the mid-sixteenth century. (Haviland 1970: 97.)

I have described the kinship terminology known for the Yucatan Maya elsewhere (Haviland 1968: 102-103). As noted above, the terms are those which were in use towards the end of the sixteenth century. Given an apparent shift away from patrilineal organization, it is reasonable to suppose that the derivative difurcate merging avuncular terms, which in a sense seem intermediate between bifurcate merging and bifurcate collateral, represent a shift towards the latter following the changes in residence and descent. The sixteenth century terms indicate alternative Iroquois-Hawaiian terms. Iroquois terms (with bifurcate merging) seem particularly consistent with unilineal organization. Hawaiian terms are more consistent with ambilineal organization (Murdock 1960: 14). Again, this would be consistent with the changes which I suspect were under way in sixteenth century Maya society.

Somewhat surprising is the shift to bifurcate collateral, rather than generation, avuncular terms. It has been suggested that, in ambilineal societies with Hawaiian terminology, avuncular terminology is commonly of generation type (Murdock 1960: 14). Among the Maya, there may have been differentiation of descent lines on the basis of collateral distance from the direct line of descent from a high-status ancestor. This would be consistent with the apparent succession to office of the previous occupant's eldest son (Tozzer 1941: 87). Such a situation has some resemblance to the collateral attenuation of rights and obligations among the members of a bilateral kindred (see Lambert 1966: 644). Murdock (1960: 6) once suggested that, in bilateral societies with kindreds, bifurcate collateral terminology may occur in lieu of lineal terminology. Both types distinguish lineal from collateral relatives. One might expect to find bifurcate collateral terminology in an ambilineal society where differentiation is made between collateral descent lines.

The hypothesis offered here requires that the change in kinship terminology began less than 100 years after the onset of the demographic catastrophe which is seen as the precipitant of this change. This might seem a rapid adjustment on the part of kinship terminology, which according to traditional anthropological thinking, could not occur until after the changes in residence and descent. However, changes in kinship terminology are known to have taken place among some modern Yucatan Maya in similar periods of time (Redfield 
1941: 197). The sixteenth century changes, moreover, were in response to a crisis situation. What I envision, then, is fairly rapid change in the sixteenth century.

On the basis of the information discussed so far, it seems clear to me that, on the eve of conquest, a patrilineal principle of descent was important in Yucatan. This is consistent with Driver's (1961: 322) observation that there is a tendancy for North American Indian societies, in which men dominate subsistence, to emphasize patrilineality. In terms of Murdock's (1949) old typology of social organization, I once classified this as an example of Guinea type (Haviland 1968: 103). This now appears to be incorrect; I would now regard Maya social organization in Yucatan, on the eve of conquest, as an example of Dakota type, which Murdock called the most widespread and typical form of patrilineal organization, including, by definition, all patrilineal societies with Iroquois cousin terminology (Murdock 1949: 236). Without getting into the pros and cons of this typology, it is sufficient to make the point that there is no element of matrilineal descent involved.

Following the introduction of Old World diseases, a population reduction of major proportions struck the Maya. The evidence suggests that this resulted in changes in residence and descent practices, which were beginning to be reflected by the kinship terms in use near the end of the sixteenth century. By this shift, Maya social organization appears to me to have evolved through something much like what Murdock (1960: 14) once called a quasi-unilineal stage, and was well on the way to an ambilineal form of organization.

To return, now, to a question posed at the outset: was there any uniformity of Maya social organization in Yucatan at the time of conquest? The question cannot be given a definitive answer. But, there is some evidence, reviewed elsewhere, (Haviland 1972 ) which suggests considerable uniformity of household composition. Second, the existence of sibs, with dispersed membership, suggests that individuals had sib-mates scattered over large areas. Indeed, many of the more than 250 patronymics associated with sibs were widely distributed over the Yucatan penninsula. Again, uniformity over a wide area is implied. Finally, it is of interest to note Murdock's (1960: 13) classification of Chorti Maya society as 
ambilineal and the possibility that Chontal Maya society was, too (Haviland 1970: 98). This suggests an arc of developing so-called ambilineal societies stretching from the Motagua River region, through the Yucatan penninsula, over into Campeche. The problem is, of course, that the Chontal, Chorti, and Yucatan Maya may have developed their ambilineal organization out of somewhat different types of precolumbian organization. Perhaps future investigation can clarify these matters.

It must be emphasized that the hypothesis presented here for a change in sixteenth century Maya social organization rests on bits and pieces of evidence, rather than firm data. At the moment, it seems to make sense in terms of the suggestions of pattern which are available. What is needed is further information to see if it continues to hold up. For, after all, today's plausible hypothesis may all too easily become tomorrow's discard.

\section{BIBLIOGRAPHY}

ADAMS, R. E. W.

1969 Maya Archaeology 1958-1968, A Review. Latin American Research Review, IV (2): 3-45.

BEALS, R. L.

1932 Unilateral Organizations in Mexico. American Antbropologist 34: $467-475$.

BuCHLER, I. y H. A. Selby

1968 Kinship and Social Organization. New York.

COE, M. D.

1965 A Model of Ancient Community Structure in the Maya Lowlands. Soutbwestern Journal of Antbropology, 21: 97-114.

1966 The Maya. New York.

Driver, H. E.

1961 Indians of North America. Chicago.

EGGAN, F.

1934 The Maya Kinship System and Cross-cousin Marriage. American Antbropologist, 36: 188-202.

GoODENOUGH, W. H.

1961 Review of Social Structure in Southeast Asia, G. P. Murdock, ed. American Anthropologist, 63: 1341-1347.

1963 Review of Matrilineal Kinship, D. W. Schneider and K. Gouth, eds. American Antbropologist, 65: 923-928.

1970 Description and Comparison in Cultural Anthropology. Chicago. 
HAVILAND, W. A.

1968 Ancient Lowland Maya Social Organization. Middle American Research Institute Publication, 26: 93-117.

1970 A Note on the Social Organization of the Chontal Maya. Ethnology, IX: 96-98.

1971 Entombment, Authority and Descent at Altar de Sacrificios, Guatemala, American Antiquity (in press).

1972 Marriage and the Family Among the Maya of Cozumel Island, 1570. Estudios de Cultura Maya, VIII: 217-26.

HeLlmuth, N. M.

1969 Preliminary Bibliography of the Chol Lacandon, Yucatec Lacandon, Chol, Itza, Mopan and Quejache of the Soutbern Maya Lowlands 1524-1969. Mimeograph, Department of Sociology and Anthropology, Brown University.

LAMBERT, B.

1966 Ambilineal Descent Groups in the Northern Gilbert Islands. American Antbropologist, 68: 641-664.

Lux, T. E.

1965 Comparative Thai Family Structures. Mimeograph, University of Vermont.

MURDOCK, G. P.

1949 Social Structure. New York.

1960 Cognatic Forms of Social Organization. Viking Fund Publications in Anthropology, 29: 1-14.

REDFIELD, R.

1941 The Folk Culture of Yucatan. Chicago.

ROMNEY, A. K.

1967 Kinship and Family. Handbook of Middle American Indians, 6: 202-237.

ROYS, R. L.

1940 Personal Names of the Maya of Yucatan. Carnegie Institution of Wasbington. Publication 523, Contribution 31.

1943 The Indian Background of Colonial Yucatan. Carnegie Institution of Washington. Publication 548.

1957 The Political Geography of the Yucatan Maya. Carnegie Institution of Washington. Publication 613.

1962 Literary Sources for the History of Mayapan. Carnegie Institution of Washington. Publication 619: 23-86.

1965 Lowland Maya Native Society at Spanish contact. Handbook of Middle American Indians, 3: 659-678. 
ROYS, R. L., F. V. SCHOLES y E. B. ADAMS

1940 Report and Census of the Indians of Cozumel, 1570. Carnegie Institution of Washington, Publication 523, Contribution 30.

THOMPSON, J. E. S.

1966 The Maya Central Area at the Spanish Conquest and Later: A Problem in Demography. Proceedings of the Royal Anthropological Institute of Great Britain and Ireland, 1966: 23-37.

TOZZER, A. M.

1941 Landas" Relación de las cosas de Yucatán: A Translation. Papers of the Peabody Museum 18. 